\title{
CONSIDERACIONES SEMIÓTICAS SOBRE LOS USOS METAFÓRICOS DE ORDEN AMBIENTAL EN EL SISTEMA DE PRODUCCIÓN DISCURSIVO DE SU SANTIDAD BARTOLOMÉ, PATRIARCA ECUMÉNICO DE CONSTANTINOPLA
}

\author{
Felipe Cárdenas - Támara \\ Universidad de la Sabana. Colombia
}

Resumen: El propósito de este trabajo es identificar el uso de metáforas existentes en el sistema de producción discursiva desplegado por el Patriarca Ecuménico de Constantinopla, su Santidad Bartolomé. Las figuras retóricas desplegadas por el patriarca expresan profundos sentidos ambientales que posibilitan la apertura y generación creativa de importantes procesos de reflexión y acción cultural y ambiental. El texto da pautas y sugiere que el lenguaje metafórico y metonímico es central a la apropiación, guías de acción, ancladas en una semiótica de la religión, atentas a reconocer las ontologías y sentidos figurados, que permiten ampliar la comprensión e interpretación del proceso de significación discursiva en el componente ambiental cuyos registros vienen del cristianismo ortodoxo.

Palabras clave: Teología bizantina - antropología de la religión - semiótica de la religión - narrativa ambiental - patriarca Bartolomé - ontología cristiana

\section{SEMIOTIC CONSIDERATIONS ON THE METAPHORICAL USES OF ENVIRONMENTAL ORDER IN THE DISCURSIVE PRODUCTION SYSTEM OF HIS HOLINESS BARTHOLOMEW, ECUMENICAL PATRIARCH OF CONSTANTINOPLE}

Abstract: The purpose of this paper is to identify the use of existing metaphors in the discursive production system deployed by the Ecumenical Patriarch of Constantinople, His Holiness Bartholomew. The rhetorical figures displayed by the patriarch express deep environmental senses that allow process of reflection and environmental and cultural action. The text gives guidelines and suggests that metaphorical and metonymic language is central to the appropriation of action guides, anchored in a semiotics of religion, attentive to recognizing ontologies and figurative senses, which allow to broaden the understanding and interpretation of the process of signification 
Keywords: Byzantine theology - anthropology of religion - semiotics of religion environmental narrative - Patriarch Bartholomew - Christian ontology

Recibido: 12.3.2019 - Aceptado: 21.11.2019

Correspondencia: Felipe Cárdenas Támara

Email: felipe.cardenas@unisabana.edu.co

Universidad de la Sabana. Colombia

ORCID ID: 0000-0002-3804-8961

\section{Introducción}

71 presente texto, situado en el llamado "giro ontológico" de la antropología (González, 2015: 39-64; Escobar, 2018: 13-219), brinda pautas para analizar la ontología ambiental existente en la teología ortodoxa y bizantina, destacando los usos metafóricos de orden ambiental que se advierten en el discurso del patriarca Ecuménico de Constantinopla, su santidad Bartolomé. El patriarca Bartolomé es considerado por diversos autores como uno de los más importantes pensadores ambientales en la actualidad (Aagaard, 2013; Cárdenas, 2017, 2018; Chryssavgis, 2016; Maros, 2017; Rusch, 2013); es el exponente de una ecología particular, básicamente desconocida en la órbita del cristianismo latino y del pensamiento antropológico y sociológico contemporáneo. El trabajo identifica algunas de las características de la "perspectiva invertida" desde la cual, la ontología de la iglesia de oriente ha buscado establecer las bases para contribuir a la solución de los problemas ambientales.

Dicha perspectiva ha sido relacionada con las llamadas teologías apofáticas. En estas, el rasgo fundamental refiere la incognoscibilidad de Dios, elemento central a la dogmática ortodoxa. La noción de incognoscibilidad plantea límites al discurso humano sobre Dios, sin que se pretenda eliminar o cancelar la reflexión y acción humana sobre la realidad o la naturaleza, puesto que el uso del lenguaje como constante humana imposibilita una total experiencia no discursiva. ${ }^{1}$ La intencionalidad de toda su estructura semiótica

1 Tanto para la ortodoxia romana como para la ortodoxia oriental, el problema del conocimiento sobre Dios quedó plasmado en el tratado cuyo título da cuenta de las complejidades del conocimiento humano al acercarse al tema de lo absoluto: De la teología mística, escrito por Pseudo Dionisio Areopagita, personaje a quien se le atribuyó durante mucho tiempo ser discípulo de San Pablo. Los escritos dionisianos y las areopagíticas se constituyen en un punto de unión entre las tradiciones teológicas de Oriente y Occidente. 
es la de instaurar los medios para que el creyente experimente la vía de unión con Dios, cuyo correlato ascético refiere la posible, real y concreta divinización del hombre, tal como lo expresa en su obra san Máximo el Confesor (Constas, 2014: 17). La vía de la unión no está interesada en ser vía de conocimiento, le interesa la experiencia de Dios, la vivencia, el sentido espiritual del camino y la participación comunitaria eclesial. Su problema fundamental es la unión con Dios en la vida del creyente y de la Iglesia. Por lo tanto, sus definiciones dogmáticas expresan la experiencia de una tradición centrada en las condiciones de posibilidad en la unión con Dios por parte de los creyentes.

El pensamiento metafórico que se explora en este artículo, en unión con los marcos interpretativos desplegados por la narrativa cristiana inspirada en una lectura de lo ambiental, se expresa como un camino fértil que denota procesos de construcción de sentidos profundos, cuya fuerza configura tanto las topologías mentales como los territorios biofísicos en la comunidad de creyentes que comparten esas estructuras culturales. En concreto, las metáforas expresiones sustantivas y nucleares al lenguaje humano, se apoyan en referentes sensoriales y metasensoriales que han sido usadas para describir, comprender y razonar sobre lo conceptual y lo abstracto, tal como ha sido reconocido en múltiples investigaciones científicas (Cf. Kövecses, 2007; Lawley y Tompkins, 2003; Lakoff y Johnson, 2003).

El diálogo con lo que se denomina iglesia ortodoxa, o iglesias de oriente, como con las iglesias no calcedónicas, tiene que partir de la identificación de la riqueza cultural de las diversas tradiciones que se pueden agrupar en las iglesias bizantinas, la Iglesia rusa, la Iglesia ortodoxa griega, la ítalo-albanesa, las Iglesia serbia, la Iglesia de Ucrania, la Iglesia serbia, la ortodoxa rumana, la católica rumana, la ortodoxa búlgara y la católica búlgara. Y en el llamado mundo de las iglesias no calcedónicas, su universo está conformado por la armenia ortodoxa, los católicos armenios, los coptos, los coptos católicos, los ortodoxos etíopes, los católicos etíopes, los ortodoxos eritreos, los ortodoxos siriacos, los ortodoxos siriacos del Malankar, los católicos sirios, los católicos sirio-malankares, y los maronistas.

Dada la complejidad del tema, el presente artículo no tiene la pretensión de agotar la discusión teórica sobre el concepto de religión en el cristianismo

Para Pseudo Dionisio, un autor sin una identificación personal precisa, existen dos vías teológicas posibles: una teología positiva o catafática que procede con afirmaciones, y otra que procede con negaciones, denominada apofática o negativa. En el horizonte de la tradición teológica ortodoxa, la primera vía conduce a cierto conocimiento de Dios, y se considera una vía imperfecta; la segunda conduce a la ignorancia total y es la vía perfecta, por tanto, la única que conviene en la experiencia de Dios, absoluto, más que absoluto e incognoscible por naturaleza (Lossky, 1982: 20). 
ortodoxo, ni pretende abarcar todos los contenidos antropológicos sobre el sentido de la cultura religiosa, de la teología ortodoxa que debe comprenderse desde el horizonte de su riqueza dogmática y desde la profundidad de sus gestos rituales (Dumas, 2003: 237-260).

\section{1.- Horizontes teóricos. metáforas religiosas y crisis ambiental}

La religión en su sentido amplio puede ser entendida como una metáfora de las metáforas. Sus expresiones culturales significan, valoran y normatizan profundos sentidos y complejas prácticas sociales que desbordan en muchos casos el campo del análisis discursivo o estrictamente analítico. Los estudios sobre la religión, la espiritualidad y el hecho religioso son uno de los temas más complejos a los que se enfrentan las ciencias sociales; su naturaleza, origen, funciones, sentidos e intencionalidades es un tema no agotado aún en sus referencias sociológicas y antropológicas (Cf. Duch, 2001; Luhmann, 2007: 9-307; Rappaport, 2001; Auge, 1988). Se puede afirmar que, a la fecha, los diversos enfoques con los cuales se ha intentado captar científicamente el hecho religioso son insuficientes. Se ha escrito mucho sobre el tema; existen esfuerzos de síntesis comparativa, téngase en cuenta, por ejemplo, la obra Readers in Comparative Religión (1976), trabajo publicado originalmente en 1958 en una edición compilada por los profesores William A. Lessa y Evon Z. Vogt. En esta obra monográfica, el tema se organiza en torno a publicaciones que abordan los orígenes y funciones de la religión, mitos y rituales, totemismo, magia y adivinación. El trabajo cuenta con nueve entradas que abordan la dinámica de la adivinación y termina la obra con cinco artículos con una sección titulada: "Portraits of Religious System". Raymond Firth, en un trabajo publicado en el libro aludido afirmaba (1976, p.126): "that no really satisfactory classification of religious behavior has yet been made". La obra carece de trabajos investigativos relativamente sistemáticos que den cuenta del hecho religioso en las grandes religiones instituidas: cristianismo, islamismo, judaísmo, e hinduismo, tendencia que se mantiene en la antropología.

El patriarca Bartolomé (1991) denota la crisis ambiental con la expresión "grito de agonía". Mediante estas palabras advierte la gravedad de los problemas ambientales que vive la humanidad. El patriarca Bartolomé, desde hace 26 años, viene desarrollando y construyendo un rico proceso comunicativo plasmado en mensajes, homilías y encíclicas, que advierten del peligro derivado de las malas decisiones ambientales que marcan el rumbo de las sociedades contemporáneas. Su mensaje, orientado a superar el estado de la crisis planetaria, destaca la importancia de la cooperación de toda la humanidad. En el ámbito del catolicismo romano, su santidad el papa Francisco 
coincide de alguna manera con sus reflexiones ambientales en torno al cuidado del planeta. En su Carta Encíclica Laudato Sí (2015), el papa Francisco cita las palabras de san Francisco de Asís, hablando del planeta como "una hermana y una casa común".

Las dos referencias anteriores ilustran, de manera sucinta, la importancia del pensamiento metafórico para referirnos a la gravedad de los problemas ambientales que, en ambas tradiciones eclesiales, constituyen uno de los pecados o males más graves que vive la humanidad. La visión realista que tiene el cristianismo sobre la presencia del mal, siempre tiene en su referencia al pensamiento de los Padres de la Iglesia, un componente relacional que vincula el accionar pecaminoso del hombre, con el dolor y el sufrimiento que vive la naturaleza y que ella misma ejerce en contra del hombre.

Los enunciados del patriarca, del papa y de gran parte de la teología de los Padres de la Iglesia, lo que recuerdan es cómo un mensaje metafórico, cuyo relacionamiento final es la generación de grandes argumentos simbólicos orientados al despliegue espiritual del hombre y la naturaleza, puede ser un gran medio para dar cuenta de los problemas ambientales y de los horizontes de sentido que estos les plantean a las sociedades contemporáneas. Debe tenerse en cuenta que el uso metafórico y el lenguaje simbólico forman parte de la vida diaria de todos los seres humanos. Desde luego, el hecho religioso es un terreno fértil para identificar y canalizar de manera fecunda lenguajes alegóricos, metafóricos y simbólicos. Como afirma Marc Auge (1988:17), lo divino-los dioses son el universo que señaliza lo simbólico, son entidades, elementos, estructuras, sentidos fundamentales para entender la estructura de la sociedad y sus formas de representación y sus ideologías.

\subsection{Ontología ambiental en el cristianismo ortodoxo.}

Para la ontología ambiental del cristianismo, la restauración de la naturaleza implica la restauración del hombre desde una antropología teomórfica que conozca y reconozca el propósito de la creación y el lugar de la humanidad en la "creación" divina. Hasta cierto punto, la uniformidad ontológica occidental de la que hablan autores tan prestigiosos como Philippe Descola (2013), Eduardo Viveiros de Castro (2010) y Bruno Latour (2007) es mucho más compleja e intrincada de lo que ellos mismos piensan. La llamada civilización occidental, también está repleta de referencias a espíritus, dioses y formas híbridas y gnósticas en el pensar y el obrar. Las detalladas lecturas ontológicas de Alejandro de Alejandría, san Atanasio, Alejandro de Lycopolis, san Ambrosio, san Ireneo de Lyon, san Agustín (En: Schaff, 2016), entre otros, en sus controversias con el arrianismo, el maniqueísmo y otras creencias para 
ellos "demoníacas", dieron cuenta de creencias que perduran hasta el día de hoy, tanto en movimientos esotéricos como exotéricos, las cuales siguen expresando un gnosticismo que tiene continuidad con el descrito por los Padres de la Iglesia. Como señala Eric Voegelin (1986), dicha gnosis, configuraría incluso las "religiones políticas" del comunismo bolchevique. A diferencia del pensamiento gnóstico, la narrativa cristiana ortodoxa, entiende que el hombre es una criatura de la creación, y que no está al margen de ella; todo lo contrario, es parte activa de la naturaleza. Como lo expresa Alexei V. Nesteruk (2003), en referencia al pensamiento de los Padres de la Iglesia: todos los elementos de la naturaleza, árboles, seres vivos y animales serán transfigurados mediante la participación del hombre. Dicha visión de futuro se apoya en los libros del Nuevo Testamento, en concreto, Romanos 8:19-21, donde San Pablo afirma: "Porque el anhelo ardiente de la creación es el aguardar la manifestación de los hijos de Dios". La restauración de la naturaleza, como expresión de la unión con Dios en el hombre, implica una acción consciente de restauración. Son contundentes las palabras de Pavel Florenski (2010:255) en ese sentido cuando afirma: “...el deterioro de la naturaleza humana trae consigo el deterioro de toda la creación, mientras que la restauración del hombre devuelve el orden a todas las criaturas". Así es que lo simbólico permite involucrar conexiones con patrones de significancia personal, comunitaria y cósmica, que se relacionan con el problema del sentido. Contrario al modelo de las ciencias naturales, lo simbólico no se centra exclusivamente en la lectura de los signos, condición que marca diferencialmente una semiótica de lo humano y lo cultural. La esencia del pensamiento metafórico y de las formas de sentido, tiene que ver con profundos procesos de comprensión que generan pautas de comunicación que no se reducen a una ontología de lo empírico. Con el uso de metáforas, las cosas y la realidad pueden ser sentidas y experimentadas mediante la alusión a un tipo de cosas en términos de otra cosa, condición que define la naturaleza de la metáfora como pensamiento analógico. Esta es en esencia la naturaleza de la metáfora que nos convoca: la crisis ambiental se expresa como la "agonía de la Tierra", "nuestra hermana y casa"; las anteriores metáforas sirven en su expresión cognitiva para aludir a la compleja realidad ambiental que vive la humanidad. En ese sentido, la metáfora capta la naturaleza esencial de una experiencia, de una realidad, de un estado o cosa. Como lo señala Luhmann (2007: 9-310) en la exposición de su teoría del sistema social-y en continuidad con toda la tradición sociológica que viene desde Durkheim-, en la fórmula de contingencia "Dios" hay siempre una ganancia de información y de sentido que revela elementos de la estructura social de una sociedad. 
Conviene precisar que la totalidad del relato humano no se agota en el marco del discurso científico contemporáneo. Una idea fundamental para entender que las visiones exclusivamente analíticas, en el fondo pueden terminar reproduciendo violencia epistémica y simbólica al marginar la significación de los modos del ser y del pensar en el despliegue argumentativo y en el fortalecimiento de prácticas sociales discursivas cuyos referentes configuran dispositivos de poder y discursos interpretativos dominantes generadoras de violencia. Como afirma Lyotard en La Condición Postmoderna (1987: 6-10): "El saber en general no se reduce a la ciencia, ni siquiera al conocimiento". Existen narratividades y planos de la realidad que dan cuenta de dimensiones de lo real imposibles de reconocer desde los marcos de las ciencias positivas. Todas las sociedades han elaborado algún tipo de lenguaje y formas de culto para referir sentidos que remiten a un orden de lo sagrado; ese orden puede ser la expresión de dimensiones ontológico-espirituales que permiten identificar "perspectivas invertidas". Dichas perspectivas son complementarias a las concepciones desarrolladas por los métodos de las ciencias positivas, los cuales, en algunas de sus escuelas y enfoques, rehúyen, — particularmente desde la influencia ejercida por la obra de Emilio Durkheim - incluir variables que tengan en cuenta, por ejemplo, los rasgos subjetivos de los actores sociales, por considerar dichas variables como obstáculos de la pesquisa científica. Se podría pensar que las raíces más profundas de la crisis ambiental, desde una lectura ontológica, metafísica y simbólica, refiere dimensiones de lo real y de la realidad que están más allá de marcos de análisis exclusivamente de orden biológico o ecológico, en el sentido de focalizarse exclusivamente en una lectura marcada por procesos biofísicos.

La dimensión ambiental que expresa la teología del patriarca Bartolomé tiene que ver con profundas preguntas existenciales, gnoseológicas y ontológicas. Nuestra comprensión de la dinámica simbólica, es decir, icónica, se expresa como aquella realidad, o gran argumento, que es "más grande que sí misma”, siguiendo el pensamiento del padre Pavel Florenski (2010).

\subsection{Dimensión religiosa y su relacionamiento ambiental.}

La conexión axiológica que ha tenido la dimensión religiosa para muchos pueblos no puede hacernos olvidar que un hecho certero es que todos los pueblos, grupos, sociedades y culturas que han existido en el planeta Tierra han estado condicionados por los sistemas de soporte ecológicos (significante material, véase Gen. 2:7). La expresión y configuración de la vida y los ecosistemas, ha sido el resultado de millones de años de evolución, proceso que tendría que reconocerse hoy a la luz de lo que se define como conciencia 
ecológica. La tensión conceptual y lógica, tanto para las religiones teístas, como no teístas, tiene que ver con la pregunta por el grado de participación del simbolismo religioso en el cuidado del planeta, y la cuestión de si este aporta actualmente un plus de sentido plasmado en acciones concretas orientadas a salvaguardarlo. La paradoja es que el planeta puede vivir con pueblos sin religión, pero ambientalmente conscientes. Lo que sería una contradicción moral y ética sería la presencia de pueblos religiosos, pero ambientalmente inconscientes o religiosamente deformados por significados anti-ecológicos.

Desde la Ilustración, el gran desafío para el pensamiento teológico ha estado mediado por el avance sin precedentes de las ciencias naturales que han abierto la posibilidad de pensar la naturaleza desde un aspecto que generó la ruptura moderna con los modos de pensar la realidad: la naturaleza se hace a sí misma sin mediación divina (natura naturans y natura naturata). En el pensamiento moderno, Dios ya no es necesario dentro del modelo explicativo, condición que no excluye el que se tome el hecho religioso como vehículo de interés semiótico, antropológico, sociológico o filosófico, entendiendo que el campo religioso es extremadamente complejo y puede comprenderse siguiendo el pensamiento de Raimon Panikkar como un "símbolo sin pretensión de contenido en el orden conceptual" (Panikkar, 2007). Con base en los trabajos e ideas de E. Durkheim, R. Otto, W. James, D.M. Edwards, E. Underhill, Joannis Scoti Erigenae, y Nicolás de Cusa, el sociólogo Pitirim Sorokin señala como "La religión se halla constituida por una serie de valores supremos expresados en un credo, objetivados por los vehículos del culto y socializados por una conducta que se adapta a las normas religiosas que unen a los miembros dentro de un mismo grupo religioso" (Sorokin: 1969:359). La religión, como sucede en todo proceso simbólico, expande y extiende el proceso de significación (Rappaport, 2001; Luhmann, 2007; Yelle, 2012). No hay límites y no hay fin en el proceso semiótico de transformación y análisis del sentido, puesto que el movimiento es un ir y venir permanente del significante al significado. Dicha semiosis, dada la constitución significativa señalada por Sorokin, puede pensarse como más problemática para lo que se define como religión, puesto que el lenguaje religioso está estructurado de prácticas sociales discursivas (el culto, el rito) que aumentan la complejidad de los sentidos gramaticales existentes en el hecho religioso.

La religión, inherente a ciertos sistemas culturales es un código de sentido arbitrario (la religiosidad) que funciona al interior de otro código arbitrario: la cultura. Por el lado de la antropología se encuentran "definiciones" sobre la religión de orden multicontextualizadas, no esencialistas, que sirven para orientar procesos investigativos. Para Clifford Geertz, (2004: 1-35), 
uno de los más influyentes antropólogos contemporáneos, la religión estaría marcada por un sistema de símbolos que actúan para establecer poderosos, y penetrantes, modos de ánimo, que son duraderos. Señala Geertz que la religión formula concepciones que destacan un orden general de la existencia marcado por concepciones con un aura de factualidad que influye de manera realista en los estados de ánimo y motivaciones de los creyentes.

Sobre la definición de la palabra religión, el trabajo de Richard Comstock (1984: 499-517) destaca cómo el término <<religión >>, mediante el cual nos queremos aproximar a los hechos religiosos en su conexión ambiental, es una invención reciente en el mundo académico. Las definiciones que se acaban de presentar permiten identificar que la religión es una experiencia humana, un hecho sociocultural con matices tanto subjetivos, objetivos, intersubjetivos y suprasubjetivos que establecen distinciones y complementariedades entre lo sagrado y lo profano, que deben comprenderse desde el horizonte de las ontologías locales como universales. El marco sígnico de la religión debe entenderse como un texto abierto al análisis semiótico y, por lo tanto, en permanente proceso de significación.

\subsection{Semiótica de la religión.}

Una lectura semiótica de la religión lee textos abiertos generados por la religiosidad y produce neotextos semióticos cargados de nuevas significaciones. Se asume como un hecho que los signos construidos mediante significantes y significados, ya sea fonemas o lexemas, no tienen significados inherentemente propios, se les imponen los sentidos dentro de un sistema semiótico de diferencias cuya fuente es la cultura humana, más que la naturaleza. Comstock, señala como Derrida, complementó el énfasis de Saussure sobre la brecha entre el signo y el sentido, mediante el uso del esquema triádico sobre el arte de la significación en términos de un signo inicial que significa a un segundo signo el cual es clarificado mediante un interpretante que también está compuesto de signos (Peirce, 1988). El interpretante está sujeto al mismo proceso a través de otro interpretante. Continúa Comstock desarrollando la idea del juego dual del significado: el significante es tanto el significante del significado que lo ha suscitado y el significado de una nueva etapa en un proceso abierto-finalizado de continua clarificación (Comstock, 1984).

Las relaciones de orden comunitario o eclesial, que suponen un marco de identidad paradigmática entre sus fieles no excluyen la expresión de relaciones sintagmáticas (Jacobson) que enfatizarían un orden de contigüidad más que de similitud. Estos enunciados preliminares enriquecen el sentido de comprensión de lo religioso, posibilitando la comprensión de la diversidad religiosa, ya 
que las relaciones de contigüidad, implican conexiones metonímicas más que metafóricas ${ }^{2}$. Los estudios religiosos han estado obsesionados con las relaciones metafóricas y han subestimado la importancia de la metonimia. Para Comstock (1984:499-517): "Las relaciones metafóricas entre palabras nos proporcionan facilidad verbal; las conexiones metonímicas añaden a nuestro conocimiento". Los cambios semánticos generados por la metonimia le dan forma a nuevos conceptos, ideas y argumentos, donde la transnominación suscita la comprensión de la realidad y la invención de conceptos para captar nuevos sentidos sobre la realidad.

El horizonte de trabajo que se viene delineando, tiene que implicar una semiótica cultural que parta de reconocer la discusión referida a la antinomia naturaleza-cultura. Como indica Zylko Boguslaw (2001: 391-408), esta cuestión se ha debatido numerosas veces en la historia de la filosofía, la antropología filosófica y la metodología de las ciencias sociales. Debe destacarse la posición de Yuri Lotman, citado por Boguslaw (2001), donde se entiende la cultura como información, y se piensa como un proceso cultural o antinatural en el sentido de establecer fronteras entre los campos de lo natural y lo cultural. Yuri Lotman, definió la cultura "como un todo de información no hereditaria y sus caminos de organización y almacenamiento" (citado en Boguslaw, 2001: 393).

Desde la noción de Lotman, la cultura es información y depende del acto procesual de la conciencia humana. Es un proceso tanto subjetivo como consciente en su carácter. El mundo externo o la "naturaleza", proporciona los materiales para los artefactos culturales; y ese mismo mundo es objeto de cognición. Por lo tanto, las ciencias naturales se constituyen en sí mismas, componentes de la cultura humana. La cultura como información es transmitida por mecanismos no genéticos y no incluye el comportamiento instintivo, como tampoco nada que esté basado en funciones como las derivadas de la noción de Pavlov de un "sistema signado primario". Ahora, la antinomia naturalezacultura, establece que la argumentación de Lotman se enfrenta a posturas naturalistas, que exploran las raíces genéticas de sistemas particulares de signos, anclados en referencias al papel de los estudios zoología, especialmente los datos de la primatología (Boguslaw, 2001: 393).

2 Define el Diccionario de la lengua española metonimia como: "Tropo que consiste en designar algo con el nombre de otra cosa tomando el efecto por la causa o viceversa, el autor por sus obras, el signo por la cosa significada, etc.; p. ej., las canas por la vejez; leer a Virgilio, por leer las obras de Virgilio; el laurel por la gloria, etc". El mismo diccionario define metáfora como: "Traslación del sentido recto de una voz a otro figurado, en virtud de una comparación tácita, como en las perlas del rocío, la primavera de la vida o refrenar las pasiones" (RAE, 2017). 
Consecuentemente, el comportamiento humano ha preservado numerosos comportamientos arcaicos estereotipados, heredados por los humanos de sus ancestros y que se reflejan en las condiciones fisiológicas (asimetría de los hemisferios) del cerebro humano; condiciones que, según ciertos mecanismos fundamentales, permiten que, para el hombre, el sistema de signos se haga presente como condición innata. En referencia a Lotman, Boguslaw (2001) recuerda que la posición de aquel se afima como antinaturalista, pero recuerda que Lotman no excluyó a la neurosemiótica de su modelo analítico. Por lo tanto, la perspectiva semiótica de Lotman no descartó los elementos de intercomunicación e interacción entre la esfera natural y la cultural. En síntesis, los elementos no culturales, como los culturales, se afectan mutuamente.

\section{Metáforas y sentidos ambientales}

En las siguientes tablas se dará cuenta, a manera de síntesis, de algunos enunciados del patriarca Bartolomé que ilustran la presencia explícita de usos lingüísticos de carácter metafórico y alegórico. Es un resumen, fundamentado sobre un total de 118 citas que aparecen en 51 documentos de los 146 textos que estructuran el sistema discursivo ambiental del patriarca. Las tablas se estructuran con base en la fuente, su texto en inglés, la traducción, el tipo de enunciado y un comentario sobre el sentido explicativo del texto metafórico utilizado ${ }^{3}$.

3 Todas las fuentes utilizadas están disponibles en el portal del Patriarcado Ecuménico de Constantinopla: https://www.patriarchate.org/. La página traduce el trabajo intelectual del patriarca escrito en griego, inglés y francés. El trabajo que hemos realizado se basa en el material traducido al inglés. El trabajo metodológicamente se estructuró usando el software para el análisis cualitativo de datos Atlas.ti 7. 
Tabla 1. Cristo como oveja, pez o vid

\begin{tabular}{|c|c|c|c|c|}
\hline Fuente & $\begin{array}{l}\text { Texto en ingles } \\
\text { de referencia }\end{array}$ & $\begin{array}{l}\text { Traducción al } \\
\text { español del texto } \\
\text { de referencia }\end{array}$ & $\begin{array}{c}\text { Tipo de } \\
\text { enunciado }\end{array}$ & $\begin{array}{c}\text { Sentido } \\
\text { explicativo }\end{array}$ \\
\hline $\begin{array}{c}1994, \\
\text { C h r i s t m a s } \\
\text { E n c y c li c a } 1 \\
\text { Message } \\
\text { CHURCH } \\
\text { AND } \\
\text { SYMBOLS } \\
\text { December }\end{array}$ & $\begin{array}{l}\text {.. Christ was } \\
\text { portrayed as a } \\
\text { pure white lamb, } \\
\text { as a fish or as a } \\
\text { vine. The four } \\
\text { E v a n e lists } \\
\text { were represen- } \\
\text { ted by an angel, } \\
\text { a lion, an ox, } \\
\text { and an eagle. } \\
\text { The Holy Spirit } \\
\text { was depicted } \\
\text { as a dove ever } \\
\text { since the Bap- } \\
\text { tism of Jesus } \\
\text { Christ in the } \\
\text { River Jordan. } \\
\text { With the passa- } \\
\text { ge of time, the } \\
\text { Church became } \\
\text { even more auda- } \\
\text { cious in making } \\
\text { use of nature's } \\
\text { symbols in or- } \\
\text { der to decorate } \\
\text { the space whe- } \\
\text { re the faithful } \\
\text { worshipped. The } \\
\text { church interior, } \\
\text { in fact liturgy } \\
\text { itself, became a } \\
\text { miniature icon } \\
\text { of the univer- } \\
\text { se, of heaven, } \\
\text { of earth, of the } \\
\text { nether world and } \\
\text { of the world to } \\
\text { come. We can } \\
\text { begin, therefore, } \\
\text { to understand } \\
\text { the concepts of } \\
\text { sacred space and } \\
\text { sacred time }\end{array}$ & $\begin{array}{l}\text {.. Cristo fue re- } \\
\text { tratado como un } \\
\text { cordero blanco } \\
\text { puro, como un pez } \\
\text { o como una vid. } \\
\text { Los cuatro evan- } \\
\text { gelistas fueron re- } \\
\text { presentados por un } \\
\text { ángel, un león, un } \\
\text { buey y un águila. } \\
\text { El Espíritu Santo } \\
\text { fue representado } \\
\text { como una paloma } \\
\text { desde el Bautismo } \\
\text { de Jesucristo en el } \\
\text { río Jordán. Con el } \\
\text { paso del tiempo, la } \\
\text { Iglesia se hizo aún } \\
\text { más audaz al hacer } \\
\text { uso de los símbo- } \\
\text { los de la naturale- } \\
\text { za para decorar el } \\
\text { espacio donde los } \\
\text { fieles rendían cul- } \\
\text { to. El interior de la } \\
\text { iglesia, de hecho, } \\
\text { la misma liturgia, } \\
\text { se convirtió en un } \\
\text { ícono en miniatura } \\
\text { del universo, del } \\
\text { cielo, de la tierra, } \\
\text { del mundo inferior } \\
\text { y del mundo ve- } \\
\text { nidero. Podemos } \\
\text { comenzar, por lo } \\
\text { tanto, a compren- } \\
\text { der los conceptos } \\
\text { de espacio sagrado } \\
\text { y tiempo sagrado. }\end{array}$ & $\begin{array}{l}\text { Alegórico-sim- } \\
\text { bólico, con ex- } \\
\text { plicación lógica } \\
\text { sobre el uso de } \\
\text { los símbolos y } \\
\text { sus propósitos } \\
\text { en la iglesia }\end{array}$ & $\begin{array}{l}\text { Los objetos } \\
\text { materiales de } \\
\text { la naturaleza } \\
\text { cumplen una } \\
\text { función gra- } \\
\text { matical y me- } \\
\text { tafórica para } \\
\text { transmitir sen- } \\
\text { tidos ontológi- } \\
\text { cos profundos } \\
\text { en la construc- } \\
\text { ción del men- } \\
\text { saje evangéli- } \\
\text { co. La estruc- } \\
\text { tura del culto } \\
\text { litúrgico está } \\
\text { marcada por la } \\
\text { influencia de } \\
\text { símbolos que } \\
\text { devienen del } \\
\text { mundo de la } \\
\text { naturaleza. }\end{array}$ \\
\hline
\end{tabular}


Tabla 2. El arca de los últimos días

\begin{tabular}{|c|c|c|c|c|}
\hline Fuente & $\begin{array}{l}\text { Texto en ingles } \\
\text { de referencia }\end{array}$ & $\begin{array}{l}\text { Traducción al } \\
\text { español del texto } \\
\text { de referencia }\end{array}$ & $\begin{array}{c}\text { Tipo de } \\
\text { enunciado }\end{array}$ & $\begin{array}{c}\text { Sentido } \\
\text { explicativo }\end{array}$ \\
\hline \multirow[t]{2}{*}{$\begin{array}{c}\text { Address } \\
\text { during } \\
\text { the official } \\
\text { opening } \\
\text { of the first } \\
\text { international } \\
\text { symposium } \\
\text { Revelation } \\
\text { and the } \\
\text { Environment } \\
\text { S e p t e m b e r } \\
22, \\
1995\end{array}$} & $\begin{array}{l}\text { We are assembled } \\
\text { on a kind of latter } \\
\text { day ark, in itself } \\
\text { a symbol that } \\
\text { would have de- } \\
\text { lighted St. John. } \\
\text { As we begin our } \\
\text { voyage, the ship } \\
\text { faces us with our } \\
\text { essential interde- } \\
\text { pendence. Here, } \\
\text { in microcosm, } \\
\text { is a truth that we } \\
\text { need to bring to } \\
\text { our distress in any } \\
\text { part of the ship: } \\
\text { the passengers di- } \\
\text { ning in first class } \\
\text { will not for long } \\
\text { escape the conse- } \\
\text { quences. }\end{array}$ & $\begin{array}{l}\text { Estamos reunidos } \\
\text { en una especie de } \\
\text { arca de los últimos } \\
\text { días, en sí misma } \\
\text { un símbolo que } \\
\text { habría deleitado a } \\
\text { San Juan. Cuan- } \\
\text { do comenzamos } \\
\text { nuestro viaje, el } \\
\text { barco nos con- } \\
\text { fronta con nuestra } \\
\text { interdependencia } \\
\text { esencial. Aquí, en } \\
\text { el microcosmos, } \\
\text { es una verdad que } \\
\text { debemos poner a } \\
\text { nuestra disposición } \\
\text { en cualquier parte } \\
\text { del barco: los pa- } \\
\text { sajeros que comen } \\
\text { en primera clase no } \\
\text { escaparán por mu- } \\
\text { cho tiempo de las } \\
\text { consecuencias. }\end{array}$ & $\begin{array}{l}\text { Alegórico-sim- } \\
\text { bólico con ex- } \\
\text { plicación lógica } \\
\text { sobre el uso de } \\
\text { los símbolos. Se } \\
\text { destaca la inter- } \\
\text { dependencia con } \\
\text { el mundo natu- } \\
\text { ral y reconoce } \\
\text { cómo en la barca } \\
\text { hay pasajeros de } \\
\text { primera y de se- } \\
\text { gunda. }\end{array}$ & $\begin{array}{l}\text { Sentido de la } \\
\text { navegación hu- } \\
\text { mana: soportes } \\
\text { ecológicos y } \\
\text { culturales. Se } \\
\text { navega en el } \\
\text { mar median- } \\
\text { te constructos } \\
\text { culturales da- } \\
\text { dos por la bar- } \\
\text { ca. }\end{array}$ \\
\hline & $\begin{array}{l}\text { A new heaven } \\
\text { and a new earth; } \\
\text { a new communi- } \\
\text { ty in a holy city; } \\
\text { a river of life and } \\
\text { a tree with leaves } \\
\text { for the healing of } \\
\text { nations. }\end{array}$ & $\begin{array}{l}\text { Un nuevo cielo y } \\
\text { una nueva tierra; } \\
\text { una nueva comu- } \\
\text { nidad en una ciu- } \\
\text { dad santa; un río } \\
\text { de vida y un árbol } \\
\text { con hojas para la } \\
\text { curación de las na- } \\
\text { ciones }\end{array}$ & $\begin{array}{l}\text { Alegórico-sim- } \\
\text { bólico con ex- } \\
\text { plicación lógica } \\
\text { sobre el uso de } \\
\text { los símbolos y } \\
\text { los propósitos } \\
\text { curativos de la } \\
\text { iglesia. }\end{array}$ & $\begin{array}{l}\text { Horizonte de } \\
\text { esperanza y cu- } \\
\text { ración }\end{array}$ \\
\hline
\end{tabular}




\begin{tabular}{|c|c|c|c|c|}
\hline Fuente & $\begin{array}{l}\text { Texto en ingles } \\
\text { de referencia }\end{array}$ & $\begin{array}{l}\text { Traducción al } \\
\text { español del texto } \\
\text { de referencia }\end{array}$ & $\begin{array}{c}\text { Tipo de } \\
\text { enunciado }\end{array}$ & $\begin{array}{c}\text { Sentido } \\
\text { explicativo }\end{array}$ \\
\hline $\begin{array}{l}\text { Address } \\
\text { during } \\
\text { the official } \\
\text { opening } \\
\text { of the first } \\
\text { international } \\
\text { symposium } \\
\text { Revelation } \\
\text { and the } \\
\text { Environment }\end{array}$ & $\begin{array}{l}\text { Symbols of the } \\
\text { End-Time combi- } \\
\text { ne with what we } \\
\text { consider possible } \\
\text { to create a field of } \\
\text { action and to fill it } \\
\text { with either hope } \\
\text { or despair. }\end{array}$ & $\begin{array}{l}\text { Los símbolos del } \\
\text { tiempo final se } \\
\text { combinan con lo } \\
\text { que consideramos } \\
\text { posible: crear un } \\
\text { campo de acción } \\
\text { y llenarlo de espe- } \\
\text { ranza o desespera- } \\
\text { ción. }\end{array}$ & $\begin{array}{l}\text { Realismo sim- } \\
\text { bólico que habla } \\
\text { de la realidad de } \\
\text { la terminación } \\
\text { de la historia hu- } \\
\text { mana }\end{array}$ & $\begin{array}{l}\text { El sentido de } \\
\text { la historia y } \\
\text { los contenidos } \\
\text { de esperanza o } \\
\text { desesperanza } \\
\text { con los que se } \\
\text { construye esa } \\
\text { historia. }\end{array}$ \\
\hline $\begin{array}{c}\text { Septem } \\
22, \\
1995\end{array}$ & $\begin{array}{l}\text { Another symbol } \\
\text { has been given to } \\
\text { us, which points } \\
\text { in this hopeful di- } \\
\text { rection, although } \\
\text { being more recent } \\
\text { it has sunk more } \\
\text { profoundly into } \\
\text { human conscious- } \\
\text { ness. The earth- } \\
\text { rise photograph } \\
\text { taken in } 1969 \\
\text { from the Apollo } \\
\text { spacecraft shows } \\
\text { the entire planet } \\
\text { sapphire blue and } \\
\text { beautiful, just as } \\
\text { no human being } \\
\text { since the dawn } \\
\text { of history had } \\
\text { ever seen it. This } \\
\text { angelic view is } \\
\text { for shadowed } \\
\text { and enlarged in } \\
\text { the Book of Re- } \\
\text { velation, when } \\
\text { John is shown the } \\
\text { heavens opened } \\
\text { and contemplates } \\
\text { a great multitu- } \\
\text { de out of every } \\
\text { nation, rejoicing } \\
\text { before the throne } \\
\text { of God. }\end{array}$ & $\begin{array}{l}\text { Otro símbolo nos } \\
\text { ha sido dado, que } \\
\text { apunta en esta di- } \\
\text { rección de esperan- } \\
\text { za, aunque siendo } \\
\text { más reciente se ha } \\
\text { hundido más pro- } \\
\text { fundamente en la } \\
\text { conciencia huma- } \\
\text { na. La fotografía } \\
\text { tomada en } 1969 \\
\text { desde la nave espa- } \\
\text { cial Apolo muestra } \\
\text { todo el planeta de } \\
\text { azul zafiro; es her- } \\
\text { moso, como nin- } \\
\text { gún ser humano } \\
\text { desde el comienzo } \\
\text { de la historia lo ha } \\
\text { visto. Esta visión } \\
\text { angélical es prefi- } \\
\text { gurada y ampliada } \\
\text { en el Libro de Apo- } \\
\text { calipsis, cuando se } \\
\text { le muestra a Juan } \\
\text { como los cielos se } \\
\text { abren y él contem- } \\
\text { pla una gran multi- } \\
\text { tud de cada nación, } \\
\text { regocijándose ante } \\
\text { el trono de Dios. }\end{array}$ & $\begin{array}{l}\text { La historia es- } \\
\text { pacial como } \\
\text { constructora de } \\
\text { símbolos de es- } \\
\text { peranza }\end{array}$ & $\begin{array}{l}\text { Reconocimien- } \\
\text { to del papel de } \\
\text { las ciencias de } \\
\text { la Tierra en la } \\
\text { generación de } \\
\text { nuevos argu- } \\
\text { mentos y sím- } \\
\text { bolos que indi- } \\
\text { can caminos de } \\
\text { esperanza }\end{array}$ \\
\hline
\end{tabular}


Tabla 3. El grito de agonía

\begin{tabular}{|c|c|c|c|c|}
\hline Fuente & $\begin{array}{l}\text { Texto en ingles } \\
\text { de referencia }\end{array}$ & $\begin{array}{l}\text { Traducción al } \\
\text { español del texto } \\
\text { de referencia }\end{array}$ & $\begin{array}{c}\text { Tipo de } \\
\text { enunciado }\end{array}$ & $\begin{array}{c}\text { Sentido } \\
\text { explicativo }\end{array}$ \\
\hline $\begin{array}{l}\text { 1997, Toast } \\
\text { during the } \\
\text { o f f i c i a } 1 \\
\text { b a n q u e t, } \\
\mathrm{S} \text { e c o n d } \\
\text { International } \\
\text { Symposium } \\
\text { E c o lo g i c a } 1 \\
\text { Crisis } \\
\text { September } 21\end{array}$ & $\begin{array}{l}\text { Obviously, this } \\
\text { is not becau- } \\
\text { se the eventual } \\
\text { danger is uncer- } \\
\text { tain, but because } \\
\text { our cooperation } \\
\text { for the aversion } \\
\text { of the danger } \\
\text { must be cons- } \\
\text { tant and must be } \\
\text { proclaimed in } \\
\text { every quarter as } \\
\text { a cry of agony } \\
\text { for the future of } \\
\text { the peoples of } \\
\text { the Black Sea } \\
\text { region. }\end{array}$ & $\begin{array}{l}\text { Obviamente, esto } \\
\text { no se debe a que } \\
\text { el peligro final } \\
\text { sea incierto, sino } \\
\text { porque nuestra } \\
\text { cooperación para } \\
\text { rechazar el peligro } \\
\text { debe ser constante } \\
\text { y debe proclamarse } \\
\text { en todo lugar como } \\
\text { un grito de ago- } \\
\text { nía para el futuro } \\
\text { de los pueblos de } \\
\text { la región del Mar } \\
\text { Negro. }\end{array}$ & $\begin{array}{l}\text { Empírico deduc- } \\
\text { tivo en diálogo } \\
\text { con las ciencias } \\
\text { naturales y en } \\
\text { referencia terri- } \\
\text { torial y regional }\end{array}$ & $\begin{array}{l}\text { Existen territo- } \\
\text { rios y ecosiste- } \\
\text { mas en el pla- } \\
\text { neta que vie- } \\
\text { nen muriendo }\end{array}$ \\
\hline
\end{tabular}

Tabla 4. Navegando en las turbulentas aguas de la vida.

\begin{tabular}{|c|c|c|c|c|}
\hline Fuente & $\begin{array}{l}\text { Texto en ingles } \\
\text { de referencia }\end{array}$ & $\begin{array}{l}\text { Traducción al } \\
\text { español del texto } \\
\text { de referencia }\end{array}$ & $\begin{array}{c}\text { Tipo de } \\
\text { enunciado }\end{array}$ & $\begin{array}{c}\text { Sentido } \\
\text { explicativo }\end{array}$ \\
\hline $\begin{array}{l}\text { 1999, June } \\
5, \text { The Halki } \\
\text { E c o l o g i c a } 1 \\
\text { Institute }\end{array}$ & $\begin{array}{l}\text { N a vig a t i n g } \\
\text { through the tur- } \\
\text { bulent waters of } \\
\text { life, the Church } \\
\text { seeks to colla- } \\
\text { borate with God } \\
\text { in His work of } \\
\text { creation by fi- } \\
\text { lling the "void" } \\
\text { and shining forth } \\
\text { the radiant light } \\
\text { of Christ on the } \\
\text { "darkness" that } \\
\text { sin has brought } \\
\text { upon the world. }\end{array}$ & $\begin{array}{l}\text { Navegando a tra- } \\
\text { vés de las turbu- } \\
\text { lentas aguas de la } \\
\text { vida, la Iglesia bus- } \\
\text { ca colaborar con } \\
\text { Dios en su obra de } \\
\text { creación llenando } \\
\text { el "vacío" y ha- } \\
\text { ciendo brillar hacia } \\
\text { adelante la luz ra- } \\
\text { diante de Cristo en } \\
\text { la "oscuridad" que } \\
\text { el pecado ha traído } \\
\text { al mundo. }\end{array}$ & $\begin{array}{l}\text { Alegórico-me- } \\
\text { tafórico: nave- } \\
\text { gación en aguas } \\
\text { turbulentas, va- } \\
\text { cío, luz, oscuri- } \\
\text { dad, pecado }\end{array}$ & $\begin{array}{l}\text { Relato realista } \\
\text { que apela a la } \\
\text { navegación en } \\
\text { "aguas turbu- } \\
\text { lentas" para } \\
\text { destacar la du- } \\
\text { reza de la vida } \\
\text { y el papel de la } \\
\text { Iglesia como } \\
\text { colaboradora } \\
\text { en la obra de } \\
\text { Dios. Refe- } \\
\text { rencia al mal } \\
\text { como oscuri- } \\
\text { dad, siendo su- } \\
\text { perado por la } \\
\text { luz de Cristo. }\end{array}$ \\
\hline
\end{tabular}


Tabla 5. Viaje de descubrimiento y revelación

\begin{tabular}{|c|c|c|c|c|}
\hline Fuente & $\begin{array}{l}\text { Texto en ingles de } \\
\text { referencia }\end{array}$ & $\begin{array}{l}\text { Traducción al español } \\
\text { del texto de referencia }\end{array}$ & $\begin{array}{l}\text { Tipo de } \\
\text { enunciado }\end{array}$ & $\begin{array}{c}\text { Sentido } \\
\text { explicativo }\end{array}$ \\
\hline \multirow[t]{2}{*}{$\begin{array}{l}\text { 1999, junio } \\
5 \text {, Message } \\
\text { of Ecumeni- } \\
\text { cal Patriarch } \\
\text { B artholo- } \\
\text { mew to the } \\
\text { Sixth Sym- } \\
\text { posium of } \\
\text { the Halki } \\
\text { Ecological } \\
\text { Institute }\end{array}$} & $\begin{array}{l}\text { As you embark on } \\
\text { this journey of dis- } \\
\text { covery and revela- } \\
\text { tion, we pray that the } \\
\text { grace of the Creator } \\
\text { and Sustainer of "all } \\
\text { things, seen and un- } \\
\text { seen" will continua- } \\
\text { lly guide you as you } \\
\text { seek to enhance the } \\
\text { beauty and wonder } \\
\text { of His creation }\end{array}$ & $\begin{array}{l}\text { Al embarcarte en este } \\
\text { viaje de descubrimiento } \\
\text { y revelación, rezamos } \\
\text { para que la gracia del } \\
\text { Creador y Sustentador } \\
\text { de "todas las cosas, vis- } \\
\text { tas y no vistas" te guíe } \\
\text { continuamente mientras } \\
\text { buscas mejorar la belle- } \\
\text { za y la maravilla de Su } \\
\text { creación. }\end{array}$ & $\begin{array}{l}\text { Alegórico- } \\
\text { metafórico: } \\
\text { navegación } \\
\text { como descu- } \\
\text { brimiento de } \\
\text { la presencia } \\
\text { de Dios en la } \\
\text { creación. }\end{array}$ & $\begin{array}{l}\text { La gracia } \\
\text { de Dios, un } \\
\text { viaje perso- } \\
\text { nal de des- } \\
\text { cubrimien- } \\
\text { to orienta- } \\
\text { do hacia la } \\
\text { belleza. }\end{array}$ \\
\hline & $\begin{array}{l}\text { Navigating through } \\
\text { the turbulent waters } \\
\text { of life, the Church } \\
\text { seeks to collabora- } \\
\text { te with God in His } \\
\text { work of creation by } \\
\text { filling the "void" and } \\
\text { shining forth the ra- } \\
\text { diant light of Christ } \\
\text { on the "darkness" } \\
\text { that sin has brought } \\
\text { upon the world }\end{array}$ & $\begin{array}{l}\text { Navegando a través de } \\
\text { las aguas turbulentas de } \\
\text { la vida, la Iglesia busca } \\
\text { colaborar con Dios en su } \\
\text { obra de creación llenan- } \\
\text { do el "vacío" y haciendo } \\
\text { brillar hacia adelante la } \\
\text { radiante luz de Cristo en } \\
\text { la "oscuridad" que el pe- } \\
\text { cado ha traído al mundo. }\end{array}$ & $\begin{array}{l}\text { A legórico- } \\
\text { metafórico: } \\
\text { navegación } \\
\text { en aguas } \\
\text { turbulentas, } \\
\text { símbolos de } \\
\text { la luz, la os- } \\
\text { curidad. }\end{array}$ & $\begin{array}{l}\text { Recono- } \\
\text { ci mi e n- } \\
\text { to de las } \\
\text { enormes } \\
\text { dificulta- } \\
\text { des que se } \\
\text { viven. Lla- } \\
\text { mado a la } \\
\text { colabora- } \\
\text { ción. }\end{array}$ \\
\hline
\end{tabular}




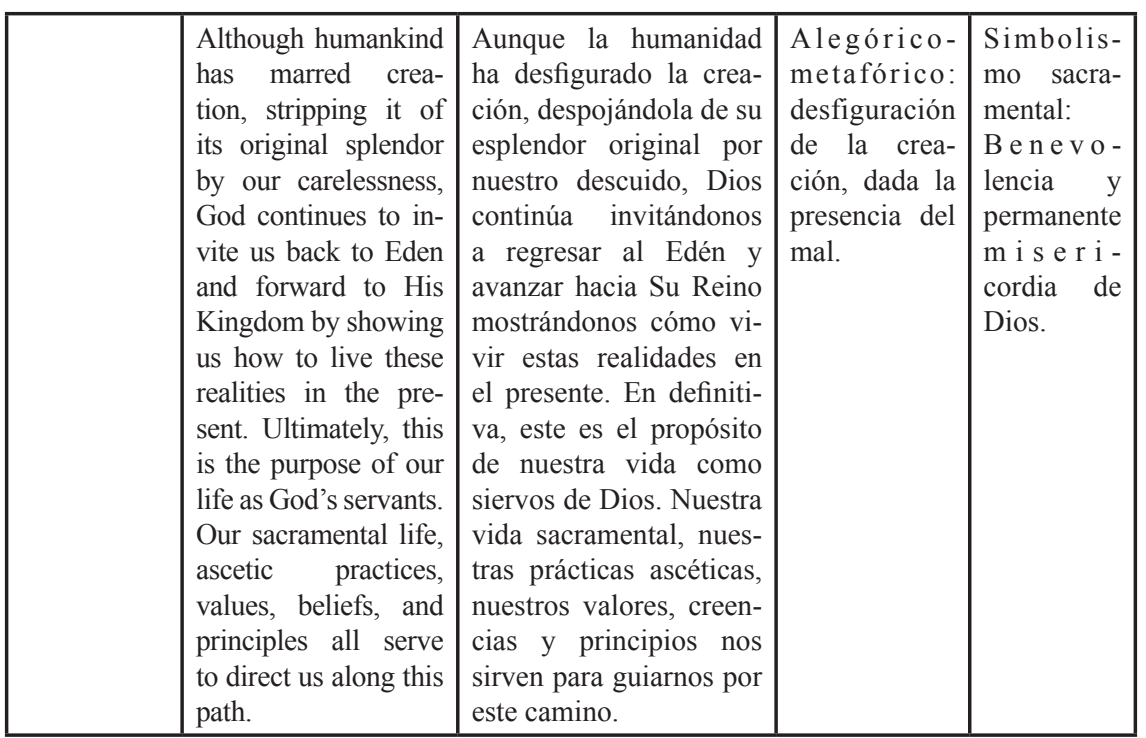

Los textos que se han presentado y que han sido generados desde el pensamiento de uno de los clérigos más influyentes de la teología ortodoxa contemporánea, el patriarca Bartolomé, devienen del uso de fuentes patrísticas y neo patrísticas. Estos textos hacen parte del sistema de producción discursivo del patriarca y configuran un horizonte semiótico centrado en el estudio de la importancia del diálogo entre la religión y la ciencia (Florio, 2000). Conforme a lo anterior, la acción humana en el mundo, en tanto capacidad subjetiva y objetiva, se reconoce como afectada por un estrato profundo, implícitamente religioso (Pannenberg, 1993: 90). El problema de Dios, de lo sagrado o de la presencia de principios divinos como expresión de un lenguaje ambiental tiene varias particularidades. En primer lugar, el tipo de metáforas religiosas usadas es cuasi inalienable con respecto del ser del hombre. En segundo lugar, la temática religiosa y ambiental desplegada en el discurso estudiado es un hecho social, histórico, cultural e individual, que se expresa con mucha fuerza en todo el corpus discursivo analizado. Por último, se hace necesario reconocer que la narrativa del patriarca se construye con los aportes de la tradición ortodoxa bi-milenaria del cristianismo y en diálogo con los rasgos constitutivos de la modernidad y la posmodernidad. La conciencia humana del emisor del mensaje ambiental proyecta en lo divino y lo divino lo proyecta en la conciencia humana, su cultura y la crisis de la sociedad contemporánea. 


\section{Semiosis de la religión en el cristianismo ortodoxo: elementos de discusión}

Como nota particular a su modo de existencia, la teología ortodoxa hace un replanteamiento radical del modo de ser del ethos occidental. A manera de ejemplo, la noción de lo político que viene de Aristóteles, y que afirma que el ser humano es un animal político, se complementa y enriquece, cuando patriarca Bartolomé y la tradición que él representa, desarrolla la idea simbólica, como gran argumento, referida a ver en el hombre un animal

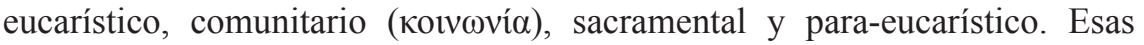
metáforas proyectan realidades que constituyen significantes y significados, como realidades materiales e inmateriales, que están en capacidad de generar formas de vida y experiencias de orden diferenciadas y mediadas por códigos culturales arbitrarios, que no son otra cosa que la cultura en toda su diversidad de manifestaciones desde la aparición del homo sapiens.

Un análisis semiótico del universo metafísico / ontológico del pensamiento ambiental inserto en la tradición discursiva del patriarca de Constantinopla Bartolomé, permite captar la fuerza de un mensaje diferenciado en tanto experiencia de orden, cuyos marcos comunicativos posibilitan conexiones educativas, políticas, culturales y ambientales ampliamente reconocidas (Cf. Bartholomew, 2008; Rusch, 2013; Chryssavgis, 2009; Chryssavgis \& Foltz, 2013).

El universo narrativo y discursivo presenta una serie de relatos que expresan las voces de una ontología local y regional, con connotaciones sociales e históricas muy interesantes dadas por la necesidad de comprender e interpretar el todo cultural occidental, desde otras narrativas, que no son las hegemónicas en el ámbito del pensamiento teológico occidental. El ángulo visual referido, se caracteriza por manejar un campo de tensiones y desafíos en tanto que la aproximación a un universo discursivo ajeno al nuestro y penetrado de teología, podría analizarse simplemente apelando a la descalificación positivista anclada en una teoría denotacionista del significado que impediría dar cuenta de realidades extralingüísticas, extragramaticales y metadiscursivas como las que se expresan en narrativas que son tanto discurso como metadiscurso (Cf. Hottois, 1997).

La tradición teológica de la Iglesia de Oriente se refiere a poder alcanzar en "la ignorancia absoluta la unión con aquel que sobrepasa a todo ser y toda ciencia" (Lossky, 1982: 20). Dionisio y su tradición, sientan las bases de las filosofías existencialistas. Como el mismo Lossky (1982:24) lo afirmó: "No queremos hacer $<<$ teología comparada $>>$ ni menos aún, resucitar las polémicas confesionales". Simplemente se hace importante 
señalar e identificar las diferencias dogmáticas entre el Oriente y el Occidente cristiano y evidenciar que el aporte dogmático de la tradición Areopagítica, como el estudio de la espiritualidad oriental, se constituye en un campo de descubrimiento importante para la semiótica, los estudios ambientales y la antropología. Su lógica binaria, marcada por la variabilidad de sus teologías positivas y negativas, genera un superávit de sentidos posibles.

Se podría afirmar que la teología ortodoxa ha mantenido la univocidad del signo divino con procesos de diferenciación históricos fieles a dicha univocidad simbólica. No existe una variedad ideológica en el discurso teológico ortodoxo; condición que no excluye álgidas discusiones "bizantinas" interesadas en defender la pureza del mensaje. Todos los teólogos ortodoxos, ya sean rumanos, griegos, rusos, serbios o americanos circunscriben su pensamiento a la patrística, horizonte de signos que abre importantes interrogantes sobre cierta condición de ahistoricidad en la teología ortodoxa (Florovsky, 1976). Lo anterior no quiere decir que la teología ortodoxa esté fosilizada en el tiempo. Por el contrario, la univocidad del pensamiento patrístico se expresa de manera dinámica en el tiempo, se actualiza y se repiensa permanentemente desde un horizonte histórico-social, del cual no pueden escaparse sus teólogos. Ahora, la univocidad del acontecimiento Jesús-Dios en su proceso interpretativo, desde los tiempos del cristianismo primitivo, ha planteado distintas circunstancias histórico-sociales marcadas por las pugnas entre escuelas teológicas. Así es como desde una base común, la escuela teológica alejandrina y la antioqueña mantuvieron pugnas teológicas. La interpretación de los libros sagrados del Antiguo y el Nuevo Testamento, como indica Dilthey, suscitó complejos escenarios de interpretación que tenían que responder comunicativamente a los diversos ethos culturales:

Tenía necesidad de la interpretación alegórica frente a los judios, para interpolar en el Antiguo Testamento la teología del Logos; frente a los gnósticos, tenía que evitar un empleo demasiado generoso del método alegórico. Siguiendo las huellas de Filón, Justino e Ireneo han intentado establecer reglas para la limitación y empleo del método alegórico. Tertuliano acoge en la misma lucha contra los judios y los gnósticos el método de Justino e Ireneo, pero desarrollan también reglas fecundas de un arte interpretativo mejor a las que no fue, sin embargo, siempre fiel. En la iglesia griega el antagonismo se expresa en principios opuestos. La escuela antioqueña explicaba sus textos ateniéndose únicamente a principios histórico-gramaticales. Así el antioqueño Teodoro veía en el Cantar de los cantares 
nada más que un epitalamio y en el libro de Job la elaboración poética de una tradición histórica. Rechazó los títulos de los Salmos y también, con respecto a una parte considerable de las predicciones mesiánicas, su relación directa con Cristo. No admitió un sentido doble del texto sino tan solo una trabazón superior entre los sucesos. Por el contrario, Filón, Clemente y Orígenes distinguían en los textos un sentido pneumático y un sentido real (Dilthey, 1944: 327).

En la actualidad, existen teólogos ortodoxos contemporáneos que trabajan y dialogan con Levinas, Heidegger y están permanentemente al tanto de los desarrollos de las ciencias naturales (Cf. Yannaras, 2004, 2011, 2012). Pero fundamentalmente, la referencia principal es la patrística, punto de partida de toda teología ortodoxa. El misterio divino y la acción del creyente son reinterpretadas desde ese elemento "univoco-trinitario" que se constituye en un interesante campo de investigación para la semiótica de lo unívoco, como del pensamiento triádico en sus referencias al mundo de lo sagrado, lo santo, lo espiritual y la religión. El énfasis místico de la espiritualidad oriental, ha sido entendido, desde el patrón occidental, como un campo inaccesible al conocimiento, marcado por el misterio inexpresable. Para el occidente cristiano, la mística y la religión son ámbitos en muchos casos incomunicados. Bergson en Deux sources citado por Lossky (1982: 8), distingue entre la $<<$ religión estática $>>$ eminentemente conservadora y no-mística y $<<$ religión dinámica $>>$ marcadamente renovadora y personal. La anterior distinción no forma parte de la tradición oriental que jamás, como nos dice Vladimir Loosky (1982), ha distinguido entre mística y teología. Y en donde teología y mística se sostienen y complementan mutuamente. Se está ante una narrativa y práctica social discursiva con importantes connotaciones políticas, educativas y noéticas. Entonces, desde la imaginación simbólica diversa occidental, se puede evocar o construir una trama narrativa, cuyo sustrato judeocristiano está en la base de la creencia representada por pueblos de tradición tanto europea como no-europea, quienes al inicio de su vida cristiana eran ajenos al iluminismo de la reforma protestante.

En el caso de la teología ortodoxa, los factores históricos que se impusieron durante varios siglos, posteriores a la caída del Imperio romano, lograron mantener la ortodoxia al margen de las influencias teológicas de galos, germanos y francos, quienes ejercieron un influjo cultural y teológico en los territorios del antiguo Imperio romano, que autores ortodoxos consideran como uno de los determinantes del cisma del año 1054 (Véase Cleenewerck, 
2007). El influjo cultural de los pueblos que ocuparon el vacío de poder generado ante la caída del imperio romano, se entiende como funesto en la determinación espiritual de Europa entre los siglos VII y VIII D. C, puesto que se introdujeron novedades teológicas, como la inserción por parte de la iglesia latina de la cláusula del Filioque, que establece la procedencia del Espíritu Santo por el Padre y el Hijo, a diferencia de la concepción trinitaria ortodoxa que considera que el Espíritu Santo procede del Padre.

Andrew Louth (2015: 193) sintetiza los principales rasgos de la teología ortodoxa afirmando que entre sus postulados se destacan: primero, la deificación del destino humano, argumento que sugiere el sentido de apertura al infinito por parte del hombre, en un destino que lo impulsa a llegar a ser como Dios en el llamado camino de la unión. El segundo punto señala que la verdadera naturaleza de la persona -en referencia a una idea que viene de san Gregorio Nacianceno (390 D.C) - no es el de un animal politikon zoon, idea que viene de la visión política de Aristóteles, sino el de una creatura zōon theoumenon, es decir, un animal y ser vivo llamado a convertirse en Dios, en un proceso de deificación, sin confinamientos, sin violencia, y que, en apertura al infinito, conduce a la auto-trascendencia personal y comunitaria. En las tradiciones cristianas orientales, el hombre está sellado por la incognoscibilidad, dada por su misma condición de criatura formada por un Dios que en su esencia es fundamentalmente incognoscible. La distinción entre esencia y energías trinitarias le posibilitarán a la teología oriental mantenerse al margen de nociones escolásticas, así como de las afirmaciones panteístas de Baruc Spinoza, por poner un ejemplo, que ligan el conocimiento de Dios a un acto racional del conocimiento de su esencia, donde naturaleza y Dios se funden entre sí (Spinoza, 1996). Las voces de pensadores heterodoxos, como Michel Foucault alejados de cualquier pretensión teológica, señalan el reconocimiento del tema que se aborda, reconociendo entre sus juicios analíticos el paisaje intelectual que se viene refiriendo, y en el que se vinculan Dios, naturaleza e incognoscibilidad. Dice Foucault:

Después de todo, no hay que olvidar que lo que, durante siglos, se ha llamado en la iglesia griega techné technon y en la iglesia romana latina ars urtium, era precisamente la dirección de conciencia; era el arte de gobernar a los hombres. Es cierto que este arte de gobernar, finalmente, ha permanecido mucho tiempo ligado a unas prácticas relativamente limitadas, incluso en la sociedad medieval, ligado a la existencia conventual, ligado a la práctica sobre todo en grupos espirituales relativamente restringidos (Foucault,1995: 5-25). 
Lo que M. Foucault no captó es que el problema administrativo de gobernar, reconocido como tal por los diferentes sínodos, está en función pragmática y condicionada por metas más profundas: la vía de unión, deificación, glorificación o santificación de los creyentes, y, por lo tanto, el gobierno eclesiástico de la iglesia se organizaba humanamente, para ejercer tareas terapéuticas, cuyo fin más profundo es la adquisición del Espíritu Santo, en lo referido a las narrativas orientales. La dimensión de gobierno terrenal, reconocida por M. Foucault en el arte de gobernar lo que no puede olvidar es que la iglesia está marcada por dos naturalezas: una divina y otra terrestre. Ella no es simplemente una estructura terrenal. Es decir, el signo Iglesia expresa sentidos y experiencias profundas que, por su constitución ontológica, no siempre pueden ser captados por los modelos, enfoques y lentes basados en la empiricidad de las ciencias sociales.

El entendimiento y comprensión de saberes y conocimientos, en este caso, sobre la teología ortodoxa, puede complementar y enriquecer el sentido del análisis semiótico. Esto se debe a que muchas de nuestras nociones analíticas, tal como lo reconocía Kant en su idealismo trascendental (Kant, 1999), se enfrentan o confluyen, por un lado, con el tema de la incognoscibilidad y los límites del conocimiento humano, y por otro, con barreras culturales y lingüísticas. Estas últimas explican las grandes divisiones que existen en el cristianismo y en la propia comprensión con la cual la mentalidad moderna o posmoderna pretende comprender la lógica del mundo de la religión.

\section{Concluyendo...condúcenos más allá del desconocimiento}

Las consideraciones semióticas sobre los usos metafóricos que se estudiaron en este artículo se centran en el horizonte de sentido que brinda la teología griega, bizantina u ortodoxa. Estas experiencias de orden, tanto en su sentido cultural y político, como en sus connotaciones religiosas, tienen la particularidad de liberar a los hombres de una Providencia Absoluta (hoy el Estado y el mercado neoliberal), noción medular al surgimiento e influencia de las teologías reformadas. En el caso de la teología ortodoxa, su intencionalidad busca cualificar su accionar buscando potenciar a las personas, los grupos sociales, la cultura local, la sociedad y los ecosistemas. El foco teológico del cristianismo ortodoxo es el amor, la verdad y la libertad, triadas que se entienden desde el ámbito de la experiencia. Se postula un vínculo con un mundo que tiene sentido cuando se comprende como una esfera dispuesta para el diálogo ente Dios y el hombre. La teología ortodoxa, a diferencia de la teología escolástica, no tiene como finalidad el constituirse en disciplina académica. 
El aporte de las ciencias sociales y de la historia a la discusión ambiental estaría en mirar críticamente las narrativas y visiones dominantes de corte naturalista que tienen la tendencia a examinar la acción humana como disruptora de un orden natural dado. Se tienen que comprender los horizontes ontológicos de pueblos ajenos al naturalismo occidental. Las consecuencias de la ontología dominante, de orden ambiental, sobre la vida de pueblos tradicionales, se pueden entender como devastadoras. Lo anterior se justifica cuando se reconoce que los estilos de vida de dichas culturas quedan supeditados a procesos de aculturación forzosa que los obliga a acoplarse a las reglas "pro-ambientales" que imponen las grandes multinacionales de lo verde y ecológico como Greenpeace y otras organizaciones. Estas organizaciones prefieren ver morir de hambre a pueblos como los Inuit en el Ártico, a concederles el "derecho" a seguir cazando focas, como expresión cultural de su seguridad alimentaria.

En el caso de religiones monoteístas, cuya perspectiva es la redención, la antropología y las ciencias de la religión tienen que mirar y penetrar necesariamente, no solamente en el campo de lo inmanente, sino que tienen que incorporar en sus lecturas, registros sincrónicos y diacrónicos, símboloslenguajes-experiencias-esencias, aparentemente más sutiles y volátiles, que sellan la unidad, el orden-desorden y la diferencia entre la inmanencia y la trascendencia: Dios supremo, dioses paralelos, ángeles, espíritus, santos y antepasados, que siguen viviendo de manera espiritual y cuyas ontologías problematizan el saber de occidente sobre lo real y la realidad. Registrar estas energías o campos de intersección entre lo inmanente y lo trascendente, remite a interesantes preguntas de investigación sobre los problemas de la significación humana, los sentidos que marcan la existencia del hombre y su incierta identidad cuyo correlato refiere las variadas ontologías, sus órdenes subyacentes, y que la antropología ha registrado como resultado de su accionar en su historia, de su galopar con el "desorden" de las cosas, y que escapan a la lógica utilitaria o estrictamente analítica que ha sido criticada por diversos autores como Georges Bataille (1974) y Michel Federico Sciacca (1960).

Para un modelamiento simbólico que agrupe los posibles registros de observación de la cultura ambiental del cristianismo, la codificación y categorización realizada se tendría que efectuar sobre un universo de textos y prácticas sociales que se configuran de manera concreta desde hace más de dos mil años. Las metáforas y alegorías se enmarcan en lo que he denominado el 'ángulo visual'4 de la espiritualidad cristiana oriental, y están en relación con

4 La noción de ángulo visual tomada de Iuri Lotman, Investigaciones semióticas, Entretextos. Revista Electrónica Semestral de Estudios Semióticos de la Cultura, No. 10 
los temas fundamentales de la tradición dogmática ortodoxa y con referentes contemporáneos cuyas expresiones discursivas en el ámbito del pensamiento ambiental se destacan en particular en el pensamiento del actual patriarca de Constantinopla.

Es vital analizar la expresión dinámica de los problemas ambientales desde la perspectiva particular de la teología de la iglesia de oriente. Ese 'otro', europeo y no-europeo, que en su universo semiótico está representado por una tradición cultural (sociofactos y mentefactos) que nos sitúa en el campo de comprensión de esquemas imaginativos y sígnicos construidos por sociedades, pueblos y grupos con una tradición narrativa, discursiva, religiosa, cultural y espiritual relativamente diferente a la del occidente latino. Como sabemos, la tradición occidental ha sido influenciada tanto por la tradición escolástica, cómo por una respuesta al pensamiento de la reforma protestante por la vía de la Contrareforma y del Concilio de Trento, que dio el tono vital del programa cultural y político de la modernidad, marcando ineludiblemente los programas de evangelización del mundo desde el siglo XVI, por la piedad mencionada. Visiones teóricas como la que se han desarrollado en este texto buscan avanzar en la comprensión y análisis de la construcción simbólica y los usos sociales de la variabilidad discursiva sobre el sentido de la crisis ambiental contemporánea. Así es como se esbozan las líneas de una antropología ambiental abierta a la exploración de ontologías metadiscursivas y abierta también a sistemas semióticos ligados al estudio, comprensión y vivencia de las narrativas de la incognoscibilidad y a la inclusión de "perspectivas invertidas" que den cuenta de los profundos sentidos que se plasman en la experiencia humana.

Ciertamente, el universo narrativo de la teología ortodoxa está marcado por la fe religiosa de la comunidad de creyentes que con su testimonio han proclamado a lo largo del tiempo su fidelidad a las verdades del evangelio que proclama al mundo y al hombre, centradas en el problema de vivir el Amor incondicional de un Dios trinitario. La importancia de la proyección de los sentidos ambientales existentes en el cristianismo tiene valiosas repercusiones teóricas y prácticas que se sustentan en toda una serie de enfoques disciplinares rigurosos que, desde las ciencias sociales, la filosofía, semiótica, historia de las religiones, mitología y teología, reconocen el valor del campo de la religión en la demarcación de aspectos vitales en la vida de los seres humanos. La "agonía de la Tierra", palabras con las que el patriarca Bartolomé refiere la crisis ambiental que vive la humanidad, nos recuerdan la importancia que ha ocupado el tema ambiental en la agenda/crescenda de la iglesia ortodoxa,

Granada, noviembre 2007. Url: http://www.ugr.es/local/mcaceres/entretextos.htm. Fecha consulta: 5 de septiembre de 2012. 
como en la expresión de afirmaciones similares en la iglesia católica romana. Una comprensión profunda de las instituciones religiosas y de los campos emocionales que forman parte de las creencias del círculo de fieles de dichas instituciones permitirá afinar el diálogo, los logros concretos y la construcción de escenarios ambientales coherentes con la dignidad contenida en la fe que proclama que el ser humano es hecho a imagen y semejanza de Dios. Se constata que existen campos de la realidad que, en sus significaciones más profundas, sus metáforas, metonimias, relatos, narrativas y símbolos, son únicamente accesibles desde los ámbitos de reflexión e inspiración que expresan dichos saberes religiosos.

Una antropología religiosa, renovada sobre el llamado giro ontológico de la antropología, es de importancia capital para enriquecer los caminos que conduzcan al despliegue espiritual del ser humano, su familia, la comunidad, y el territorio. Esta debe estar atenta a comprender y estudiar los contenidos y expresiones vitales perceptibles y no perceptibles en los mensajes, rituales, creencias, dogmas, prácticas, cánones y todo el universo de signos y sentidos configuradores a estos sistemas culturales.

\section{BIBLIOGRAFÍA}

AAGAARD, A.M. (2013). The Ecumenical Patriarch in a European Context. The witness of Bartholomew I: Ecumenical Patriarch. William G. Rusch. (Editor). Cambridge: Wm. B. Eerdmans Publishing Co.

AUGE, M. (1988). Dios como objeto. Barcelona: Gedisa.

BARTHOLOMEW, Patriarch. (2008). Encountering the mystery. Understanding Orthodox Christianity today. New York: Doubleday. ---(1991). Toastduringtheofficialbanquet, SecondInternational Symposium. Ecological Crisis. Ecumenical Patriarchate. En https://www.patriarchate. org/environmental-addresses/-/asset_publisher/47ISmr00STje/content/ toast-during-the-official-banquet-second-international-symposium/ pop_up?_101_INSTANCE_47ISmr00STje_viewMode=print\&_101_ INSTANCE_47ISmr00STje_languageId=el_GR Accedido el 22 de marzo de 2018.

BATAILLE, G. (1974). Obras escogidas. Barcelona: Barral.

BOGUSLAW, Z. (2001). "Culture and Semiotics: Notes on Lotman's Conception of Culture". New Literary History 32: 391-408.

BULGAKOV, S. (2012). Unfading Light, trans. Thomas Allan Smith. Grand Rapids. MI: Eerdmans. 
CÁRDENAS-TÁMARA, F. (2017) “La raíz ontológica de la crisis ambiental. El magisterio de su santidad Bartolomé". Theologica Xaveriana 183 (2017): 35-61, https://doi. org/10.11144/javeriana.tx67-183.rocams

--- (2018) "La restauración del cosmos sagrado en el cristianismo ortodoxo". Byzantion Nea Hellás, (37), pp. 327-340, https://byzantion.uchile.cl/index. $\mathrm{php} / \mathrm{RBNH} / \mathrm{article} / \mathrm{view} / 51565 / 53964$

COMSTOCK, W. R, (1984). "Toward Open Definitions of Religion". Journal of the American Academy of Religion 52: 499-517.

CHRYSSAVGIS, J. (Ed) (2016). Bartholomew: Apostle and Visionary. Nashville: W Publishing Group.

--- (Ed) (2009). Cosmic grace. Humble prayer. The Ecological Vision of the Green Patriarch Bartholomew. Grand Rapids: Eerdmans Publishing.

CHRYSSAVGIS, J; FOLTZ, B. (Eds). (2013). Toward an Ecology of Transfiguration. Orthodox Christian Perspectives on Environment, Nature and Creation. New York: Fordham University Press.

CLEENEWERCK, L. (2007). His Broken Body. Understanding and Healing the Schism between Roman Catholic and Eastern Orthodox Churches. Washington: Euclid University Press.

DESCOLA, P. (2013). The Ecology of Others. Chicago: Procky Paradigm Press.

DILTHEY, W. (1944). "Estructuración del mundo histórico por las Ciencias del Espíritu", en W. Dilthey, El mundo histórico. México: Fondo de Cultura Económica.

DUCH, L. (2001). Antropología de la religión. Barcelona: Editorial Herder.

DUMAS, F. (2003). "El gesto litúrgico: un análisis semiológico". Signa: Revista de la Asociación Española de Semiótica 12, 237-260.

ESCOBAR, A. (2018). Otro posible es posible: Caminando hacia las transiciones desde Abya Yala/Afro/Latino-América.

FIRTH, R. (1976). "Portraits of Religious System". Lessa, William and Vogt, Evon (Editores). Reader in Comparative Religion. An Anthropological Approach. New York: Harper \& Row.

FLORENSKI, P. (2010). La columna y el fundamento de la Verdad. Salamanca: Ediciones Sígueme.

FLORIO, L. (2000). Mapa Trinitario del Mundo. Actualización del tema de la percepción del Dios trinitario en la experiencia histórica del creyente. Salamanca: Secretariado Trinitario.

FLOROVSKY, G. (1979). Ways of Russian Theology, 2 vols. Belmont, MA: Nordland.

FOUCAULT, M. (1995). ¿Qué es la crítica? Crítica y Aufklärung”, en: Daimon, Revista de Filosofía, Murcia, $\mathrm{N}^{\circ} 11$, pp.5-25. 
FRANCISCO, papa. (2015). Carta Encíclica Laudato Sí. Sobre el cuidado de la Casa Común, marzo de 2018, https://w2.vatican.va/content/dam/francesco/ pdf/encyclicals/documents/papa-francesco_20150524_enciclica-laudatosi_sp.pdf

GEERTZ, C. (2004). "Religion as a Cultural System". Anthropological Approaches to the Study of Religion. Ed. By Michael Bainton, London: Tavistock Publications.

GONZÁLEZ V, y SERGIO A. (2015). “Antropología y el estudio de las ontologías a principios del siglo XXI: sus problemáticas y desafíos para el análisis de la cultura”. Estudios sobre las Culturas Contemporáneas. XXI, núm. 42: 39-64.

HOTTOIS, G. (1997). Historia de la filosofía del Renacimiento a la Postmodernidad. Madrid: España.

JAMES, W. (1994). Las variedades de la experiencia religiosa. Estudio de la naturaleza humana. Madrid: Ediciones Península.

KANT, I. (1999). Fundamentación de la metafisica de las costumbres. Madrid: Espasa-Calpe.

KÖVECSES, Z. (2007). Metaphor. New York: Oxford University Press.

KOHN, E. (2013). How forest think: toward an anthropology beyond the human. Los Angeles: University of California Press.

LAKOFF, G. y JOHNSON, M. (2003). Metaphors we live by. Chicago: The University of Chicago Press.

LATOUR, B. (2007). Nunca fuimos modernos: ensayos de antropología simética. Buenos Aires: Siglo XXI.

LAWLEY, J. y TOMPKINS, P. (2013). Metaphors in Mind. Transformation through Symbolic modelling. London: The Developing Company Press.

LESSA, William and VOGT, Evon. (1976). Reader in Comparative Religion. An Anthropological Approach. New York: Harper \& Row.

LOSSKY, V. (1982). Teología mística de la Iglesia de Oriente. Barcelona: Herder.

LOTMAN, I.M. (2007). "Investigaciones semióticas". Entretextos. Revista Electrónica Semestral de Estudios Semióticos de la Cultura, No. 10. Granada, septiembre de 2012, http://www.ugr.es/local/mcaceres/ entretextos.htm

LOUTH, A. (2015). Modern Orthodox Thinkers. From the Philokalia to the present. London: Society for promoting Christian Knowledge.

LUHMANN, N. (2007). La religión de la sociedad. Madrid: Editorial Trotta.

LYOTARD, J.F. (1987). La condición postmoderna Informe sobre el saber. Madrid: Editions de Minuit- Ediciones Cátedra S.A.

MAROS, A. (2017). "The Ecological Theology of the Ecumenical Patriarch Bartholomew I". International Journal of Orthodox Theology 8:1. 
MARTÍN-VELASCO J. (1993). Introducción a la fenomenología de la Religión. Madrid: Cristiandad, marzo de 2008, https://www.ucursos. cl/derecho/2010/2/D1CLFDRP/33/material_docente/previsualizar?id_ material $=309884$.

MAXIMOS THE CONFESSOR. (2014). On difficulties in the Church fathers: The Ambigua. Editado y traducción, Nicholas Constas. Cambridge: Harvard University Press. Dumbarton Oaks medieval library.

NESTERUK, A. (2003). Light from the East. Theology, Science, and the Eastern Orthodox Tradition. Minneapolis: Augsburg Fortress.

PANNENBERG, W. (1993). Antropología en perspectiva teológica. Salamanca: Verdad e Imagen.

PANNIKAR, R. (2007). Mito, fe y hermenéutica. Barcelona: Herder.

PEIRCE, C. (1988). "Algunas Consecuencias de cuatro incapacidades". Charles S. Peirce, El hombre, un signo (El pragmatismo de Peirce), José Vericat (trad., intr. y notas), Barcelona: Critica.

RAPPAPORT, R. (2001). Ritual y religión en la formación de la humanidad. Madrid: Cambridge University Press.

RUSCH, W. (Ed) (2013). The Witness of Bartholomew I. Ecumenical Patriarch. Grand Rapids: Eerdmans Publishing.

SCIACCA, M.F. (1961). La Filosofía Hoy, Madrid: Editorial Luís Miracle.

SOROKIN, P. (1969). Sociedad, cultura y personalidad, Madrid: Aguilar.

SPINOZA, B. (1996). Tratado Teológico-Político. Madrid: Alianza Editorial.

VIVEIROS DE CASTRO, E. (2010). Metafisicas caníbales. Lineas de antropología postestructural. Buenos Aires: Katz Editores.

VOEGELIN, E. (1986). Las religiones políticas. Madrid: Editorial Trotta.

YANNARAS, C. (2004). Postmodern Metaphysics. Brookline (MA): Holy Cross Orthodox Press.

--- (2011). Relational Ontology. Brookline (MA): Holy Cross Orthodox Press.

--- (2012). The Meaning of Reality. Essays on Existence and Communion, Eros and History. Los Angeles (CA): Sebastian Press.

YELlE, R. (2012). Semiotics of Religion: Signs of the Sacred in History. New York: Cambridge Press. 